\title{
I just played one on TV ...
}

$\mathrm{G}$ uidelines for physicians and other health care professionals about ethical interactions with industry are not unique. ${ }^{1}$ Historically, such guidelines centre on the complex relationship with the pharmaceutical sector. However, as content experts and opinion leaders, health care professionals are now much sought after spokespeople for other industries. Just look at Dr. Oz.

Seventeen years ago, before reality television, health-information blogs and social media, an article in CMAJ commented on medicine becoming another form of mass entertainment, with physicians serving as paid actors in expensive productions. ${ }^{2}$ That time has come to pass. And while we have conflict of interest guidelines for physicians involved with the pharmaceutical industry, there is very little to guide physician-media interactions. Such guidelines might not only provide ethical guidance to physicians, they could also help mitigate medical misinformation.

Examples of health care professionals who attempt to navigate the line between medical practitioner and celebrity are growing: we now have The Doctors, Dr. Phil and Celebrity Rehab with Dr. Drew. These shows attempt to balance credibility and commercial appeal, but unfortunately, in mainstream media, that balance can shift toward the sensational as opposed to the scientific.

For example, The $\mathrm{Dr}$. Oz Show has received 2 Emmy awards alongside widespread criticism and growing concerns from many health care professionals. A recent episode, "GMO Foods: Are They Dangerous to Your Health?," featured Jeffrey Smith, a Dr. Oz expert on issues related to food safety and author of Genetic Roulette, who says genetically modified foods may cause serious diseases, including cancer. Smith's comments prompted an open letter to the show's producers from Dr. Bruce Chassy, professor emeritus at the University of Illinois, who states "As a

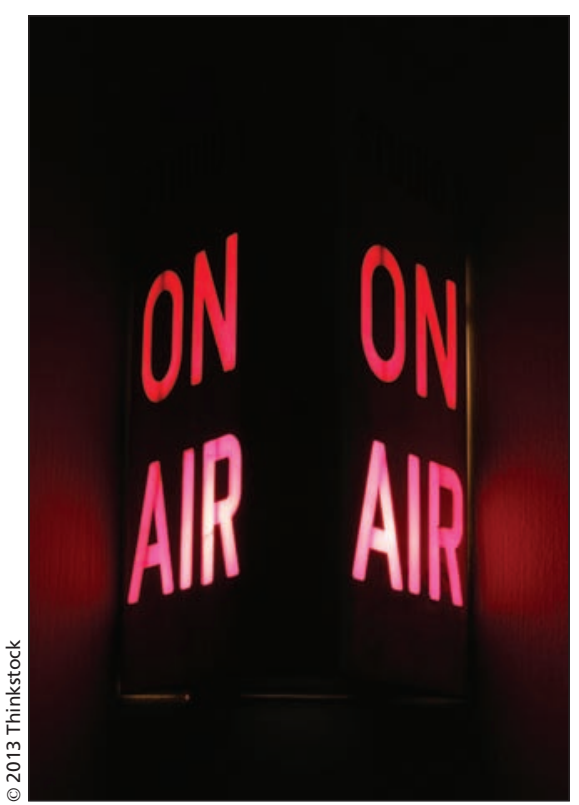

public sector scientist, researcher and academic administrator with more than 40 years' experience, I am appalled that any medical professional would give a platform to the likes of Mr. Jeffrey Smith to impart health information to the public. Mr. Smith has no accredited or formal education in any health, nutrition, or other related science fields." Chassy goes on to state the show's tactics "fall short of even the lowest standards of media and medical ethics."

But what are these standards? If only we knew. If such guidelines do exist, they are certainly not as accessible as those related to the pharmaceutical industry.

Physicians have noted there are unanswered questions and that professional self-regulation is needed. ${ }^{4}$ We need to be proactive on this issue: national regulating bodies must establish at minimum guidelines in the interest of maintaining professionalism.

Those engaged in research want to ensure that important scientific knowledge gets translated to the public accurately and meaningfully. However, we are not immune to the draw of being on television or seeing our names in a national newspaper. My coauthor and I are a case in point. We were approached by agencies interested in reality shows targeting weight issues, as that is both our research interest and a topic of fascination with the viewing public. While the appeal was clear and the perks not insignificant, in the end we declined; what makes for good television does not always adhere to the best standards of care. But the roles will be filled by others and the flow of misinformation will continue.

Mark Twain said "Be careful about reading health books. You may die of a misprint." ${ }^{5}$ That is certainly true in this new era of medicine as entertainment. Consumers need to apply common sense to any type of endorsed quick fix and health care practitioners need to be aware of how health information is packaged to the public. With this issue, it is both buyer and seller beware.

\section{Valerie H. Taylor MD PhD}

Associate Professor, Psychiatry

University of Toronto

Toronto, Ont.

Mary Forhan PhD

Assistant Professor

University of Alberta

Edmonton, Alta.

\section{References}

1. Mitchell PB. Winds of change: growing demands for transparency in the relationship between doctors and the pharmaceutical industry. Med J Aust 2009; 191:273-5.

2. Myers MG. Drug may have caused huge number of deaths: lessons learned during an encounter with The Fifth Estate. CMAJ 1996;155:772-5.

3. Chassy B. Letter to Dr. Oz Show producers. Academics Review; 2012 Available: http://academics review.org/2012/10/letter-to-dr-oz-show-producers -by-bruce-chassy-phd/.

4. Jain S.H. Practicing medicine in the age of Facebook. N Engl J Med 2009;361:649-51.

5. Ayres A. editor. Toronto $(\mathrm{ON})$ : The wit \& wisdom of Mark Twain. Harper Collins; 1987:97.

\section{CMAJ 2013. DOI:10.1503/cmaj.122103}

Do you have an opinion about this article? Post your views at www.cmaj.ca. Potential Salon contributors are welcome to send a query to pubs@cmaj.ca. 